\title{
Nutrient intakes during pregnancy, lactation and after the cessation of lactation in a group of Australian women
}

\author{
By RUTH M. ENGLISH AND NANCY E. HITCHCOCK \\ Nutrition Section, Commonwealth Department of Health, \\ Australian Institute of Anatomy, Canberra ACT
}

(Received I8 December 1967-Accepted 21 May 1968)

\begin{abstract}
I. The dietary intakes of twenty-six women were investigated during their first pregnancy, at 6-8 weeks post-partum and at 6 months post-partum or after the cessation of breast-feeding. 2. Of this group, sixteen subjects were apparently breast-feeding satisfactorily at 6-8 weeks post-partum, as judged by the average weekly weight gain of their infants (202 $\mathrm{g}$ ).

3. Changes in food consumption and nutrient intake were studied, together with changes in body-weight and activity. The subjects did not consume more calories during pregnancy. It appeared that this was a result of dietary advice received plus some curtailment of activity during pregnancy. There was an increase in intake of nutrients during lactation.

4. Intakes of iron during the third trimester of pregnancy and of ascorbic acid during lactation were $1 \cdot 9 \pm 0.3 \mathrm{mg}(\mathrm{I} 6 \%)$ and $26 \pm 7.3 \mathrm{mg}(26 \%)$ respectively below the allowances recommended by the (Australian) National Health and Medical Research Council. The significance of these intakes is discussed.

5. No difference was detected in the diets during pregnancy of women who breast-fed compared with those who did not.
\end{abstract}

This study reports the nutrient intakes in a group of healthy women during their first pregnancy and lactation; their body-weights and activities over the reproductive cycle were known. Dietary recommendations for pregnancy and lactation have been made by such bodies as the (USA) National Research Council: Food and Nutrition Board (1964), the Canadian Council on Nutrition (I964), and the (Australian) National Health and Medical Research Council: Nutrition Committee (I965). These appear to have been based mainly on physiological considerations. The limitations of the recommendations have been pointed out by the authorities making them and by others. For example, Hytten \& Leitch (1964) stated that 'physiological information is insufficient to define needs in respect of all the variations that occur in ordinary life, or indeed in respect of most of them'. Hytten \& 'Thomson (196I) commented that 'there is no need to appeal to physiology when devising allowances intended as social targets; that is, the quantities of nutrients which, if taken by most of the people in a large population, will safeguard health. Such allowances may be specified by reference to the diets of persons known to be healthy.' We have already noted that the need for information about the actual food consumption of healthy people was recognized at the Tenth Pacific Science Congress in 1963 (Hitchcock \& English, 1966). It was for the purpose of obtaining information on the quality and quantity of food chosen by healthy women in their own homes during and after a reproductive cycle, and to observe changes in intake during this period, that this study was made.

Many studies of the diets of pregnant women have been made and these have been summarized by WHO (1965). Fewer studies have been made of diets of lactating 
women. Hitchcock \& English (1966) have listed those reported in the literature. It would appear that only one study has been made of the food consumption of the same women during pregnancy, lactation and after lactation and this was concerned with specially selected women. Shukers, Macy, Donelson, Nims \& Hunscher (1931) studied three mothers in the USA at intervals throughout a complete reproductive cycle. The women were 'wet nurses', all of whom had remarkably high milk yields, the average daily yield of one being $3^{\cdot}{ }_{3} 1$. It was found that during lactation the food consumption was approximately $60 \%$ greater than during pregnancy and the immediate post-lactation period.

In the present study changes in food consumption by the subjects are considered together with changes in body-weight and activity. The observed nutrient intakes during pregnancy and lactation are compared with dietary allowances recommended by the (Australian) National Health and Medical Research Council: Nutrition Committee (1965).

\section{EXPERIMENTAL}

The subjects were apparently healthy primigravidae of average age $24 \cdot 8$ years (range $18-37$ ) at the time of the first interview. All were under medical supervision during pregnancy and as a group could be considered to be of good economic status. Eighteen of the subjects had been employed as office workers (stenographer, typist, clerk or receptionist) and three had been shop assistants. The remaining five were two nurses, a teacher, a nutritionist and a librarian. Three were living in the house of a relative and the other twenty-three were in their own homes. None of the latter had any domestic help, but all were well supplied with labour-saving devices, such as electric washing-machines, vacuum cleaners and floor polishers. All of the expectant mothers had been advised by their obstetricians or a clinic sister to have a daily rest. Nine subjects had been advised by their obstetricians to take some form of moderate exercise, such as a daily walk. A number of the subjects were taking mineral and vitamin supplements on medical advice; the supplements were not included in the calculations of the nutrient intakes.

The dietary investigation was conducted over a period of 15 months from November 1960 to February 1962. At the commencement of the study all the subjects were attending a hospital prenatal clinic, to which they had been referred by their medical practitioners. Originally thirty women were interviewed, twenty in the second trimester of pregnancy and ten in the third. Four subjects did not complete the study and values for their consumption have been included only in a comparison of the average daily intakes of nutrients during the second and third trimesters (Table 2).

A 7-day dietary record was kept by the twenty-six subjects during the third trimester of pregnancy, at 6-8 weeks post-partum and at 6 months post-partum, or for those still breast-feeding, I month after weaning. Twenty subjects completed dietary records during the second trimester. The amounts of foods were recorded in standard household measures. The procedure adopted for obtaining the records has been given in a previous paper (Hitchcock \& English, I966).

The subjects were weighed lightly clad and without shoes during each period of 
record-keeping and the weights of the infants at birth and at the two periods studied after birth were recorded. Statements of usual pre-pregnant weight were obtained from the subjects and their weights in the last week of pregnancy were obtained from medical practitioners' records. A subtraction of $0.9 \mathrm{~kg}$ was made from these values to allow for the weight of clothing. The subjects were also questioned about changes in activity, appetite and food habits and dietary instructions received. In the third trimester of pregnancy each subject completed a form, listing the amount of time normally spent in various activities throughout the day.

The average daily intakes of calories, protein, fat, calcium, iron, vitamin A, thiamine, riboflavine, nicotinic acid equivalent and ascorbic acid were calculated from the dietary records, by means of the food composition tables of Osmond \& Wilson (I96r), Wilson (196I) and Bowes \& Church (1952).

\section{RESULTS}

The twenty-six subjects gave birth to healthy infants with an average weight of $3.2 \pm 0.09 \mathrm{~kg}$. At $6-8$ weeks post-partum sixteen subjects $(62 \%)$ were fully breastfeeding their infants. The average weekly weight gain of the breast-fed infants was $202 \pm 15^{.6} \mathrm{~g}$ compared with $187 \pm 13^{.} \mathrm{Ig}$ for the bottle-fed infants. This difference was not statistically significant. From 8 weeks onwards some supplementary food was given to all the breast-fed infants.

Meal pattern. All the subjects normally ate three meals a day with three betweenmeal snacks. Sixteen $(60 \%)$ usually consumed a breakfast consisting of a cereal dish, with or without toast, and a beverage; the remainder usually had a two-course breakfast of cereal plus a cooked dish, consisting of two eggs, or an egg and bacon, or a chop, or steak, or tomatoes. Baked beans or spaghetti, with toast, was eaten occasionally.

Lunch was normally eaten in the home. It consisted of sandwiches or a salad, a piece of fruit, or cake, or biscuits, and tea or coffee. The main meal of the day was usually served at night. It normally comprised a meat dish with vegetables, and a simple dessert, such as canned fruit or jelly, with custard, ice cream or cream.

Snacks were normally eaten at mid-morning, at mid-afternoon, and before bedtime. These consisted of tea, coffee or a milk drink and cake, sweet biscuits, savoury biscuits and cheese, a sandwich, or fruit. Most of the subjects drank and enjoyed milk as a beverage and had two or three servings of fresh fruit daily. Four subjects frequently ate snack foods such as chocolates, sweets and potato crisps, which made a considerable contribution to the daily calorie intake. Alcoholic beverages were occasionally taken by a small number of the subjects.

The only consistent change in meal habits during pregnancy was a reduction in the number of between-meal snacks at 6-8 weeks post-partum by the subjects who were not lactating, and at 6 months post-partum by all subjects.

Nutrient intake during pregnancy, lactation and after cessation of lactation. Values for the average daily intake of nutrients, the average height, weight and age of the twenty-six subjects, together with the Australian dietary allowances for pregnant, lactating and non-pregnant women, are presented in Table $\mathrm{I}$. The average calorie intake of the twenty-six subjects in the third trimester of pregnancy was $2020 \pm 65 \mathrm{kcal}$ 


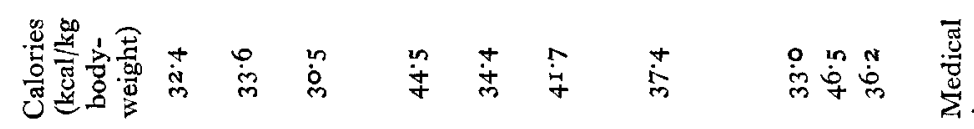

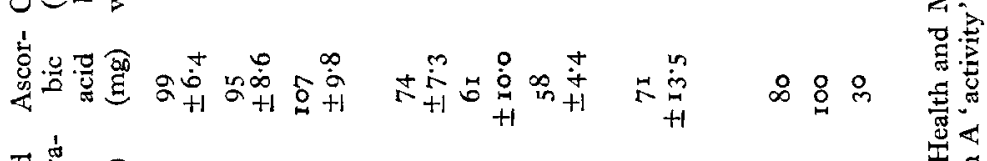

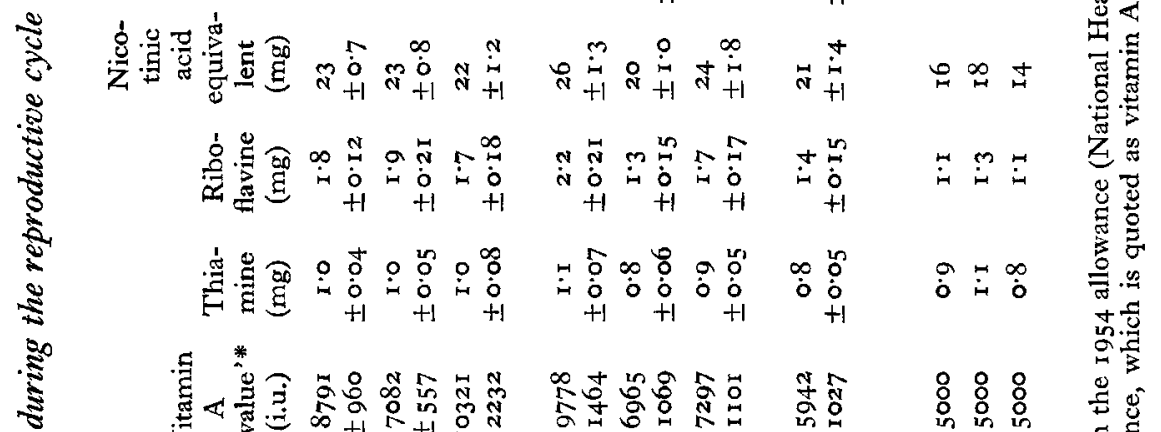

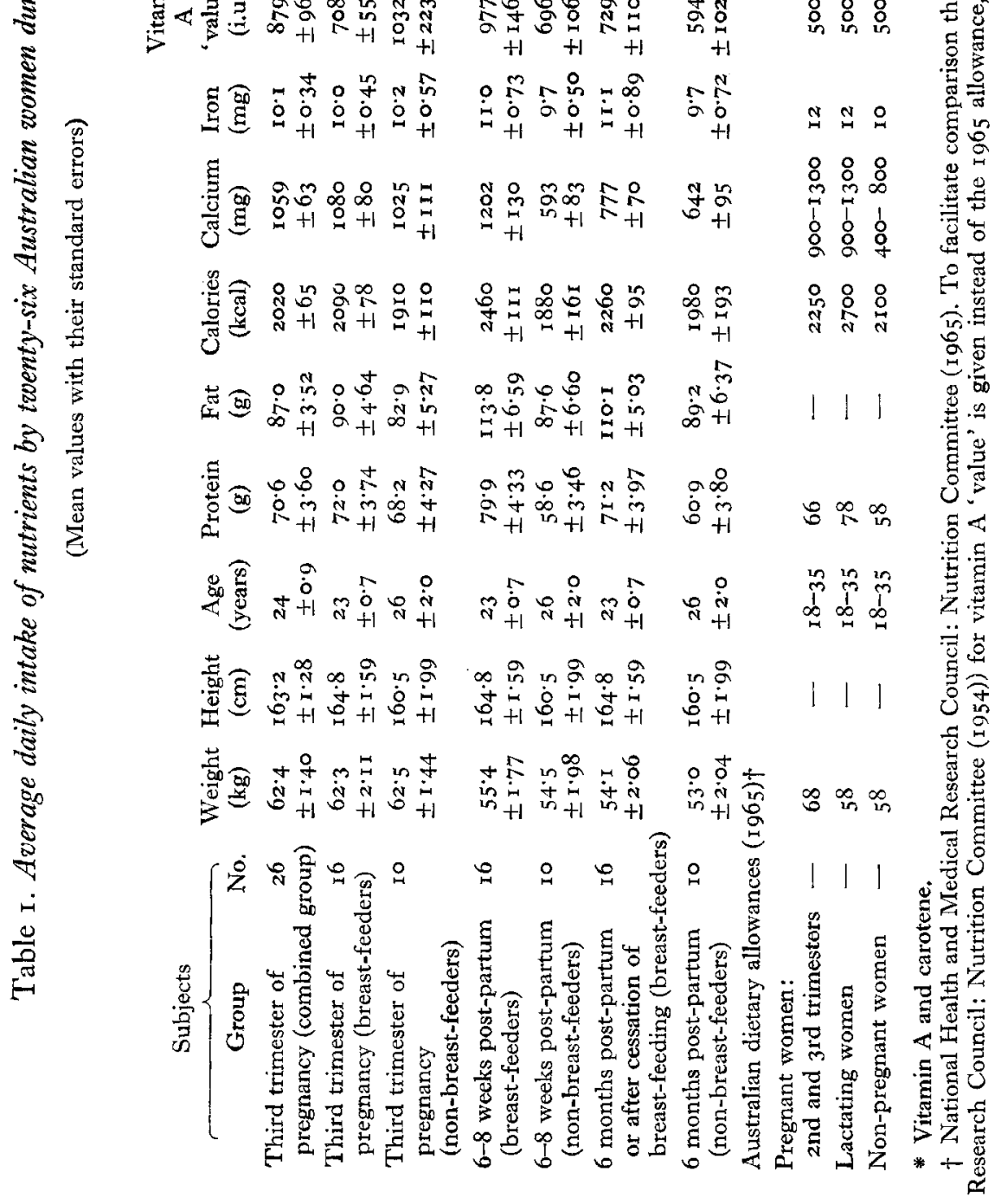


$(32.4 \mathrm{kcal} / \mathrm{kg})$, that of the sixteen subjects who subsequently breast-fed $2090 \pm 78 \mathrm{kcal}$ $\left(33^{\circ} 6 \mathrm{kcal} / \mathrm{kg}\right)$, and that of the ten subjects who did not subsequently breast-feed $1910 \pm 1$ Io $\mathrm{kcal}(30.5 \mathrm{kcal} / \mathrm{kg})$. None of the differences in the nutrient intakes of these two groups were statistically significant.

At 6-8 weeks post-partum the intake of the women who were breast-feeding had increased to $2460 \pm$ III kcal $(44.5 \mathrm{kcal} / \mathrm{kg})$, this increase in calorie intake being significant at the $\mathrm{I} \%$ level of probability. The intake of those not breast-feeding was $\mathrm{r} 880 \pm \mathrm{I} 6 \mathrm{r} \mathrm{kcal}\left(34^{\circ} 4 \mathrm{kcal} / \mathrm{kg}\right)$, which was not significantly different from their calorie intake in pregnancy.

At 6 months post-partum or after the cessation of breast-feeding the intake of the subjects who had breast-fed had decreased to $2260 \pm 95 \mathrm{kcal}(4 \mathrm{r} \cdot 7 \mathrm{kcal} / \mathrm{kg})$ and the intake of those who had not had increased to $1980 \pm 193 \mathrm{kcal}(37.4 \mathrm{kcal} / \mathrm{kg})$. Neither of these changes was statistically significant. The only survey period during which the average calorie intakes of the two groups were significantly different was at 6-8 weeks post-partum $(t<0.01)$.

The intake of other nutrients followed these trends. The observed nutrient intakes of the subjects were of similar order of magnitude to the allowances recommended by the (Australian) National Health and Medical Research Council (1965), except for the iron intake during the third trimester of pregnancy (I0. $\pm 0.34 \mathrm{mg}$ ), which was $16 \%$ below the allowance, and the ascorbic acid intake during lactation ( $74 \pm 7 \cdot 3 \mathrm{mg}$ ), which was $26 \%$ below. Most of the calorie intakes were similar to the allowances when adjustments were made for the lighter body-weights of the subjects of this study. The calorie allowance is adjusted by approximately $25 \mathrm{kcal}$ for every $\mathrm{kg}$ difference in body-weight from that of the Reference Woman, for women weighing between 40 and $65 \mathrm{~kg}$ ((Australian) National Health and Medical Research Council: Nutrition Committee, r965).

Nutrient intake during the second and third trimesters of pregnancy. Dietary records were completed by twenty of the original thirty subjects during the second as well as the third trimester. The average daily intakes of nutrients calculated from those two sets of records are given in Table 2. The average calorie intake was $2150 \pm 64 \mathrm{kcal}$ during the second trimester, and $2030 \pm 80 \mathrm{kcal}$ in the third. The difference was not statistically significant.

Influence of dietary advice on food pattern. Most of the subjects stated that they had changed their food patterns during pregnancy. The possibility that the changes had been made as a result of dietary advice was investigated. Twenty-one of the subjects had received some dietary advice from a medical practitioner. This took the form of advice to restrict calorie intake, or the handing out of a 'pregnancy diet chart', advising increased intake of milk, cheese, eggs, fruit and vegetables and restriction of high-carbohydrate and fried foods. Three of the subjects had been given low-calorie diets (1000-1 $200 \mathrm{kcal}$ ) during the third trimester of pregnancy. Four more subjects said they had been advised by a clinic sister or by a friend to include more milk, fruit and vegetables in their diet. The one remaining subject said she had not received any dietary advice.

Twenty-two subjects stated that they had responded to this advice by increasing 
620

Ruth M. English and Nancy E. Hitchcock

1968

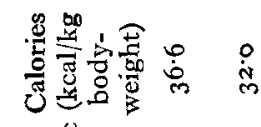

:

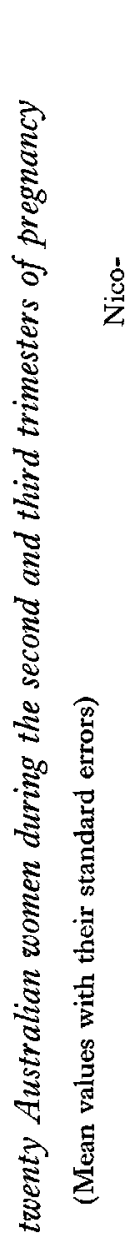

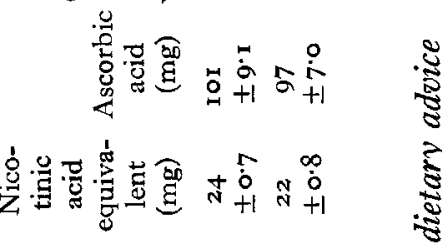

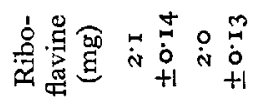

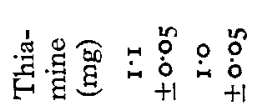

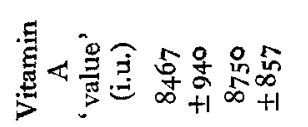

苞

苋苟

है

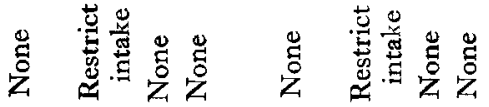

高

है

छั

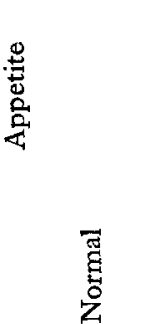

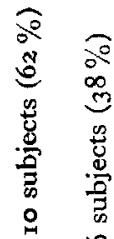

s.

尊

范

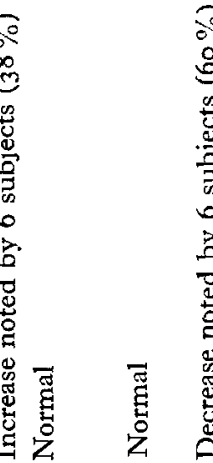

8
0
8
0
0
3
3
0

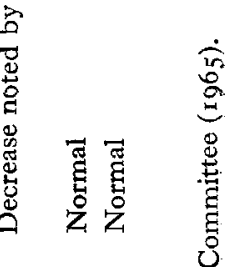

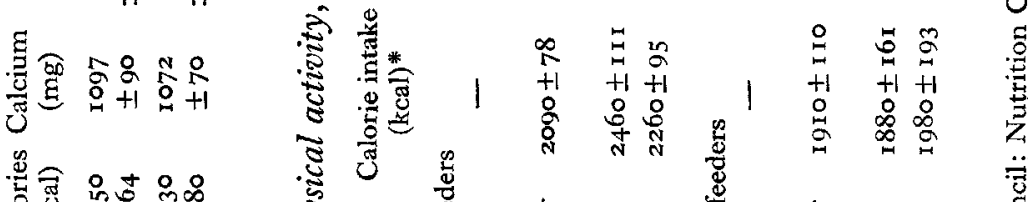

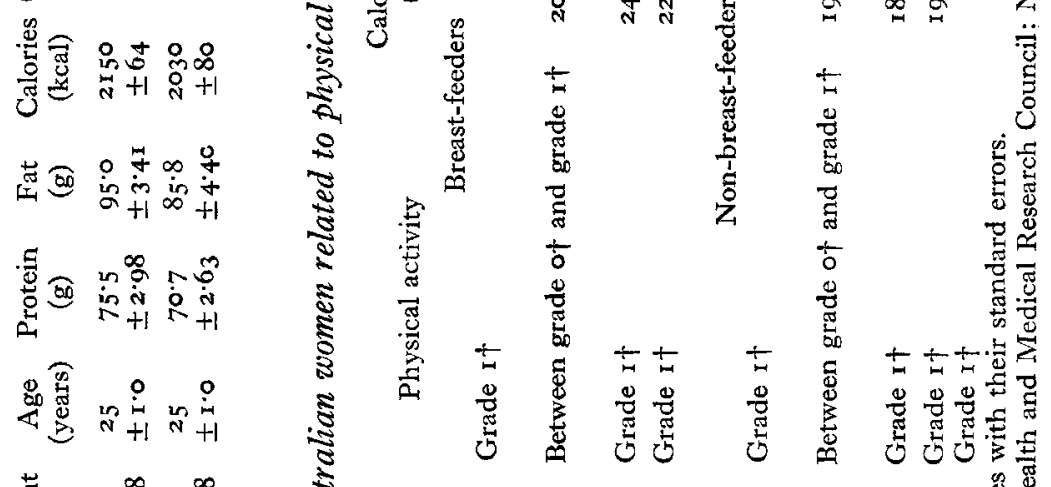

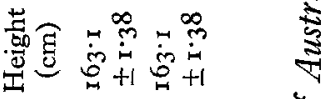

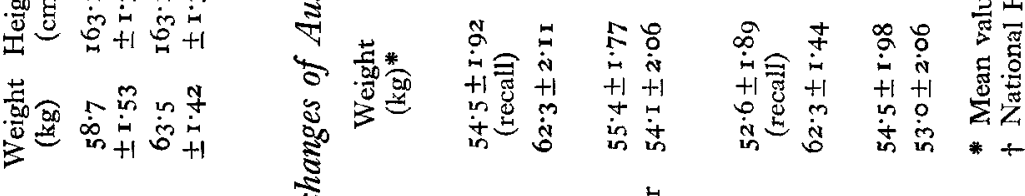

密

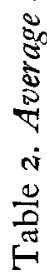

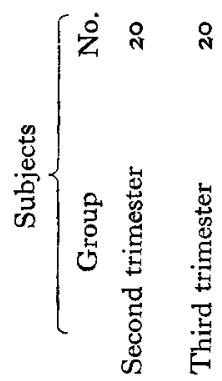

章

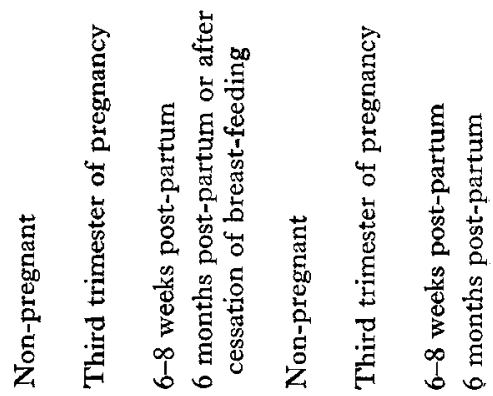


their milk consumption during pregnancy; three made no change. One said she drank less milk than when non-pregnant, but the reason for this was not recorded. Twelve subjects said they consumed more fruit and vegetables, and sixteen said they consumed smaller amounts of fried foods and of high-carbohydrate foods, such as cakes and biscuits. Two of the three subjects who were advised to consume low-calorie diets followed the advice, but the third stated that she was unable to comply because of hunger.

So far as could be ascertained, no specific dietary advice was received after parturition, although it is a generally accepted belief in the community that extra food, particularly milk, is beneficial when breast-feeding. All the subjects who were breastfeeding stated that they consumed more milk during this time than during pregnancy or after breast-feeding had ceased.

Appetite. The subjects were questioned about changes in appetite during pregnancy and lactation. Seventeen of the twenty-six subjects claimed to have noticed an increase in appetite towards the end of the first or in the second trimester of pregnancy. This increase was still noted by three of these subjects in the third trimester while the other fourteen claimed a decrease in appetite. Two subjects said their appetites were greater in the third trimester and the remaining seven subjects had not noticed any change. Our findings support the view that an increase in appetite in early pregnancy may be a common phenomenon (Taggart, I96r). Only six of the sixteen subjects who were breast-feeding noted any increase in appetite at this time although our results show that all had increased their food consumption.

Physical activity. All twenty-six subjects had been working in paid employment up to the time when attendance at the prenatal clinic had commenced, usually at 3-4 months of gestation.

It was generally admitted that the level of activity during the third trimester of pregnancy was less than that before or during early pregnancy. In the third trimester the daily pattern of activity was to spend $\mathrm{I} \cdot 5 \mathrm{~h}$ at light household cleaning tasks, $0.5 \mathrm{~h}$ dressing and undressing, $0.5 \mathrm{~h}$ laundering, $2.0 \mathrm{~h}$ in meal preparation and its associated cleaning and washing dishes. Sometimes some gardening (average $3^{\circ} \mathrm{O} \mathrm{h}$ weekly), or some shopping with transport usually by car (average $2.5 \mathrm{~h}$ weekly), would be done, or a short walk (average $5 \cdot 5 \mathrm{~h}$ weekly) would be taken. Most subjects had a rest during the day (average $1 \cdot 9 \mathrm{~h}$ ). The remainder of the day and evening $(6 \cdot 5 \mathrm{~h})$ was spent sitting, while sewing, reading, knitting, talking or listening to the radio. An average of $9.5 \mathrm{~h}$ was spent in bed at night.

The activity of these subjects was judged to be between grade $\circ$ (arbitrarily, basal metabolism $+\frac{1}{3}$ ) and grade $\mathrm{I}$ of the definitions of levels of activity in Dietary Allowances for Australians (National Health and Medical Research Council: Nutrition Committee, r 965 ). (Grade I: sleep $8 \mathrm{~h}$, dressing and undressing I h, sitting $8 \mathrm{~h}$, walking slowly $2 \mathrm{~h}$, standing $5 \mathrm{~h}$. For women, includes occupations such as light household duties and typing.)

At 6-8 weeks post-partum, whether breast-feeding or not, all subjects claimed to be more active than during the third trimester of pregnancy. More time was spent at laundering and general infant care; no morning or afternoon rest was taken; and less 
time was spent sleeping. Complaints of tiredness appeared to be more common from the subjects who were breast-feeding than from those who were not. At 6 months post-partum more time was available to all subjects for leisure activity. The infants took less time to feed and the subjects' day generally was more 'organized'. More time was then spent visiting, walking and gardening, and sports such as tennis, which had been discontinued during pregnancy, were resumed.

The level of activity at 6-8 weeks and 6 months post-partum was judged to be similar to that described for grade I level of activity (National Health and Medical Research Council: Nutrition Committee, I965).

Weight changes. Changes in body-weight as a result of pregnancy were similar in the breast-feeding and non-breast-feeding groups. The average weight gain for the combined groups during the whole of the pregnancy was $10 \cdot 3 \mathrm{~kg}$.

From 6-8 weeks to 6 months post-partum the breast-feeding and non-breastfeeding subjects showed an average decrease in weight of $I \cdot 3$ and $I \cdot 5 \mathrm{~kg}$ respectively. At 6 months post-partum the average body-weight of the combined groups $(53.6 \mathrm{~kg})$ had returned to the level of the estimated pre-pregnant weight $(53.8 \mathrm{~kg})$. In Table 3 weight changes related to values for calorie intake, physical activity, dietary advice received and changes in appetite, are given.

Breast-feeding. During pregnancy all the twenty-six subjects had expressed a desire to breast-feed. However, five subjects did not establish breast-feeding during their stay in hospital. Another five subjects, who had satisfactorily breast-fed their infants in hospital, abandoned breast-feeding between 2 and 6 weeks post-partum, because the infant was receiving insufficient milk.

\section{DISCUSSION}

\section{Nutrient intake}

During the third trimester of pregnancy the average calorie intake of the combined group was $2020 \mathrm{kcal}$. This calorie intake is similar to those recorded by Moore, Purdy, Gibbons, Hollinger \& Goldsmith (1947); Darby, McGanity, Martin, Bridgforth, Densen, Kaser, Ogle, Newbill, Stockell, Ferguson, Touster, McClellan, Williams \& Cannon (1953) and Murphy \& Wertz (1954) in the USA and by Guggenheim, Ilan, Vago \& Mundel (1960) in Israel, but falls below those recorded by Thomson (1958) in the UK and by Hankin, Burden \& Symonds (1964) in Australia, which are respectively 600 and $300 \mathrm{kcal}$ greater. With one exception (Thomson, 1958), the subjects of these other studies included both multigravidae and primigravidae.

The breast-feeding group at 6-8 weeks post-partum had an average calorie intake of $2460 \mathrm{kcal}$. This was $370 \mathrm{kcal}$ more than that during the third trimester of pregnancy $(2090 \mathrm{kcal})$ and $200 \mathrm{kcal}$ more than the intake after the cessation of breast-feeding $(2260 \mathrm{kcal})$. The $370 \mathrm{kcal}$ represents an increase of $18 \%$. This is much less than the increase of $60 \%$ noted by Shukers et al. (193I) in a group of 'wet-nurses' in Detroit, as might be expected. The calorie intake of the breast-feeders $(2460 \mathrm{kcal})$ is similar to that found for a group of Australian women by Hankin, Symonds \& Cellier (I965), who concluded that a daily diet containing $2500 \mathrm{kcal}$ was adequate for the maintenance 
of breast-feeding, and to our own previously reported results for another group (Hitchcock \& English, r966).

\section{Comparison of observed nutrient intakes with Australian recommended dietary allowances}

Knowledge of the optimum nutritional requirements of mother and foetus during pregnancy and of the lactating mother is far from complete (WHO, I965). At present, food habits which result in intakes of nutrients similar to those recommended by the (Australian) National Health and Medical Research Council are generally acknowledged to be adequate. The intakes of iron in the third trimester of pregnancy and ascorbic acid in lactation were $\mathrm{I} \cdot 9 \pm 0.34 \mathrm{mg}(\mathrm{I} 6 \%)$ and $26 \pm 7 \cdot 3 \mathrm{mg}(26 \%)$ respectively below the dietary allowances for those nutrients but, since most of the women were consuming medicinal iron as a supplement, their actual intakes were considerably in excess of recommended allowances and it is not possible to make any judgement about the adequacy of the diet itself in respect of iron. So far as ascorbic acid is concerned, it can only be said that both mothers and infants were healthy and the failure to achieve recommended intakes suggests that they may be set at an unnecessarily high level and do not provide suitable social targets for the general population. The allowance during lactation for ascorbic acid, which is 3.3 times that set for the nonpregnant woman, appears to be particularly high.

\section{Weight changes}

The average weight gain for the subjects in pregnancy $(10.3 \mathrm{~kg})$ was similar to average weight gains reported from Europe and the USA, which are between 10 and I $2 \mathrm{~kg}$ (WHO, I965). The gain was less than the weight gain of $12.5 \mathrm{~kg}$, quoted by Thomson \& Billewicz (1957) as being associated with the most favourable clinical experience, in a group of women whose food consumption was regulated by appetite during pregnancy. It is possible that the lower weight gains of our subjects $(10 \cdot 3 \mathrm{~kg})$ were influenced by dietary advice from their obstetricians.

\section{Physical activity}

It is generally agreed that the intensity of activity usually decreases during pregnancy (Thomson \& Hytten, I966). In early pregnancy women often complain of nausea and lethargy. In the second half of pregnancy intensive or prolonged activity is handicapped by increased size of the body. Activity may be further reduced on the advice of a 'concerned' husband or relative-particularly in primigravidae. This decrease in energy expenditure due to reduced activity may be partly offset by increased energy required to maintain and move a heavier individual.

FAO (1957), when considering calorie requirements, stated that 'The extra calorie needs imposed by pregnancy can, however, be covered in two ways, either by increased food intake or in part at least by reduced physical activities... and well-to-do primipara with few domestic responsibilities may achieve energy balance by cutting down physical activities and so not require many additional calories from food.' This appears to have been the case in our study. All subjects claimed to have reduced their 
activity in pregnancy below the pre-pregnant level, especially during the third trimester. Other workers have reported a decrease in energy expenditure during pregnancy (Shukers et al. 1931; Thomson \& Hytten, 1961; Hytten \& Leitch, 1964).

\section{REFERENCES}

Bowes, A. de P. \& Church, C. F. (1952). Food Values of Portions Commonly Used. Philadelphia, Pa: College Offset Press.

Canadian Council on Nutrition (1964). Can Bull. Nutr. 6, I.

Darby, W. J., McGanity, W. J., Martin, M. P., Bridgforth, E., Densen, P. M., Kaser, M. M., Ogle, P. J., Newbill, J. A., Stockell, A., Ferguson, M. E., Touster, O., McClellan, G. S., Williams, C. \& Cannon, R. O. (1953). J. Nutr. 51, 565 .

FAO (1957). F.A.O. nutr. Stud, no. I5.

Guggenheim, K., Ilan, J., Vago, T. \& Mundel, G. (1960). Br. F. Nutr. 14, 347.

Hankin, M. E., Burden, J. K. \& Symonds, E. M. (1964). Aust. N.Z. Yl Obstet. Gynaec. 4, 49.

Hankin, M. E., Symonds, E. M. \& Cellier, K. M. (1965). Aust. N.Z. Yl Obstet. Gynaec. 5, 86.

Hitchcock, N. E. \& English, R. M. (1966). Br. F. Nutr. 20, 599.

Hytten, F. E. \& Leitch, I. (I964). The Physiology of Human Pregnancy. Oxford: Blackwell Scientific Publications.

Hytten, F. E. \& Thomson, A. M. (r96r). In Milk: The Mammary Gland and its Secretion. Vol. 2, p. 3. [S. K. Kon and A. T. Cowie, editors.] New York: Academic Press Inc.

Moore, M. C., Purdy, M. B., Gibbons, E. J., Hollinger, M. E. \& Goldsmith, G. (1947). F. Am. diet. Ass. 23, 847 .

Murphy, G. H. \& Wertz, A. W. (1954). F. Am. diet. Ass. 30, 34.

National Health and Medical Research Council: Nutrition Committee (1954). Med. F. Aust. ii, I 3.

National Health and Medical Research Council: Nutrition Committee (1965). Dietary Allowances for Australians. Canberra: Department of Health.

National Research Council: Food and Nutrition Board (1964). Publs natn. Res. Coun., Wash. no. I 146.

Osmond, A. \& Wilson, W. (196r). Tables of Composition of Australian Foods. Canberra: Department of Health.

Shukers, C. F., Macy, I. G., Donelson, E., Nims, B. \& Hunscher, H. A. (r93 I). F. Nutr. 4, 399.

Taggart, N. (196r). Proc. Nutr. Soc. 20, 35.

Thomson, A. M. (1958). Br. J. Nutr. 12, 446.

Thomson, A. M. \& Billewicz, W. Z. (1957). Br. med. J. i, 243.

Thomson, A. M. \& Hytten, F. E. (1961). Proc. Nutr. Soc. 20, 76.

Thomson, A. M. \& Hytten, F. E. (1966). In Nutrition. Vol. 3. Nutritional Status: Assessment of Application, p. I03. [G. H. Beaton and E. W. McHenry, editors.] New York and London: Academic Press Inc.

WHO (1965). W.H.O. Tech. Rep. Ser. Wld Hlth Org. no. 302.

Wilson, W. (r961). Simplified Food Composition Tables. Canberra: Department of Health. 